\title{
Mathematical Simulation of the Thermodynamic Processes Associated with the Vapour-Injected Scroll Compressor
}

\author{
Ion Zabet ${ }^{1, *}$, Gratiela Maria Tarlea $^{2}$ \\ ${ }^{1}$ Center of Technology and Engineering for Nuclear Project, 409, Atomistilor Street, Magurele, Ilfov, Romania, \\ zabeti@router.citon.ro \\ ${ }^{2}$ Technical University of Civil Engineering Bucharest, 66 Blv. Pache Protopopescu,Bucharest, 021414, Romania, \\ gratiela.tarlea@gmail.com
}

\begin{abstract}
Both the major energetic crisis and the global warming, which influence the worldwide economy and the future of the society, determine the development of energetic and ecological performances of both the refrigeration equipment and air conditioning systems. Thus, there is a worldwide supported effort made in order to decrease the carbon dioxide emissions resulted from the burning of fossil fuels and the other greenhouse effect gas emissions. This article presents a refrigeration system design model using a vapour injection scroll compressor and tube in tube evaporators working with refrigerant $\mathrm{R} 407 \mathrm{C}$. The refrigerant circuit comprises of a main evaporator, a secondary evaporator (for the injection process), scroll compressor, condenser and five expansion valves. Furthermore it uses $\mathrm{R} 407 \mathrm{C}$ as refrigerant. The secondary refrigerant for both the main and the secondary evaporator is a $50 \%$ concentration solution of propylene-glycol and water. Secondary circuit comprises of a pump, an electric boiler, an expansion vessel and a by-pass circuit made of many stop valves. The condenser is cooled with mains water.
\end{abstract}

\section{Introduction}

This paper proposes a mathematical model of a refrigeration system design model using a vapour injection scroll compressor and tube in tube evaporators using EES software [1], creating a suitable geometry, setting up the cases (choosing solvers, numerical solution methods, etc.), making the calculations with EES, and comparing results to known experimental data. The mathematical model was validated through experimental bench made at Thermodynamics Laboratory of the University of Liège [2].

\section{Description of the mathematical model}

Mathematical simulation of the thermodynamic processes associated with the vapour-injected scroll compressor is presented in Fig. 1.

Initial parameters used in the simulation model are: evaporation pressure, injection pressure, condensation pressure, refrigerant injection temperature, evaporation overheating and sub-cooling temperature, room air temperature, secondary refrigerant temperature on the inlet and outlet of the evaporator and on the condenser inlet and outlet lines as well as the condenser, compressor and evaporator specific parameters (for the evaporation and injection processes).
The parameters resulting from the mathematical calculations are: compressor wall temperature, refrigerant temperature on the compressor discharge line, refrigerant mass flow rate in the refrigeration system, injection refrigerant mass flow rate, compressor mechanical power, overall compressor efficacy, volumetric efficiency, compressor isentropic efficiency, compressor compression ratio, heat conveyed by the compressor to the environment, refrigerant loss in the compressor, overall heat-transfer coefficients for each component of the refrigeration plant (compressor, condenser and evaporator), COP, condenser and evaporators efficacy, number of heat-transfer units for both the evaporators and the condenser, evaporation refrigerating capacity, injection refrigerating capacity, condensation refrigerating capacity and the refrigerant temperature on the evaporators inlet. Mathematical simulation model of the refrigeration system with vapour-injected digital scroll compressor allows the estimation of the thermodynamic efficiency and the properties in a simple manner and with a reduced number of parameters.

Table 1 shows the values of the parameters associated with the mathematical simulation model of the vapour-injected scroll compressor.

The detailed equations of the mathematical model are presented in [1]. 


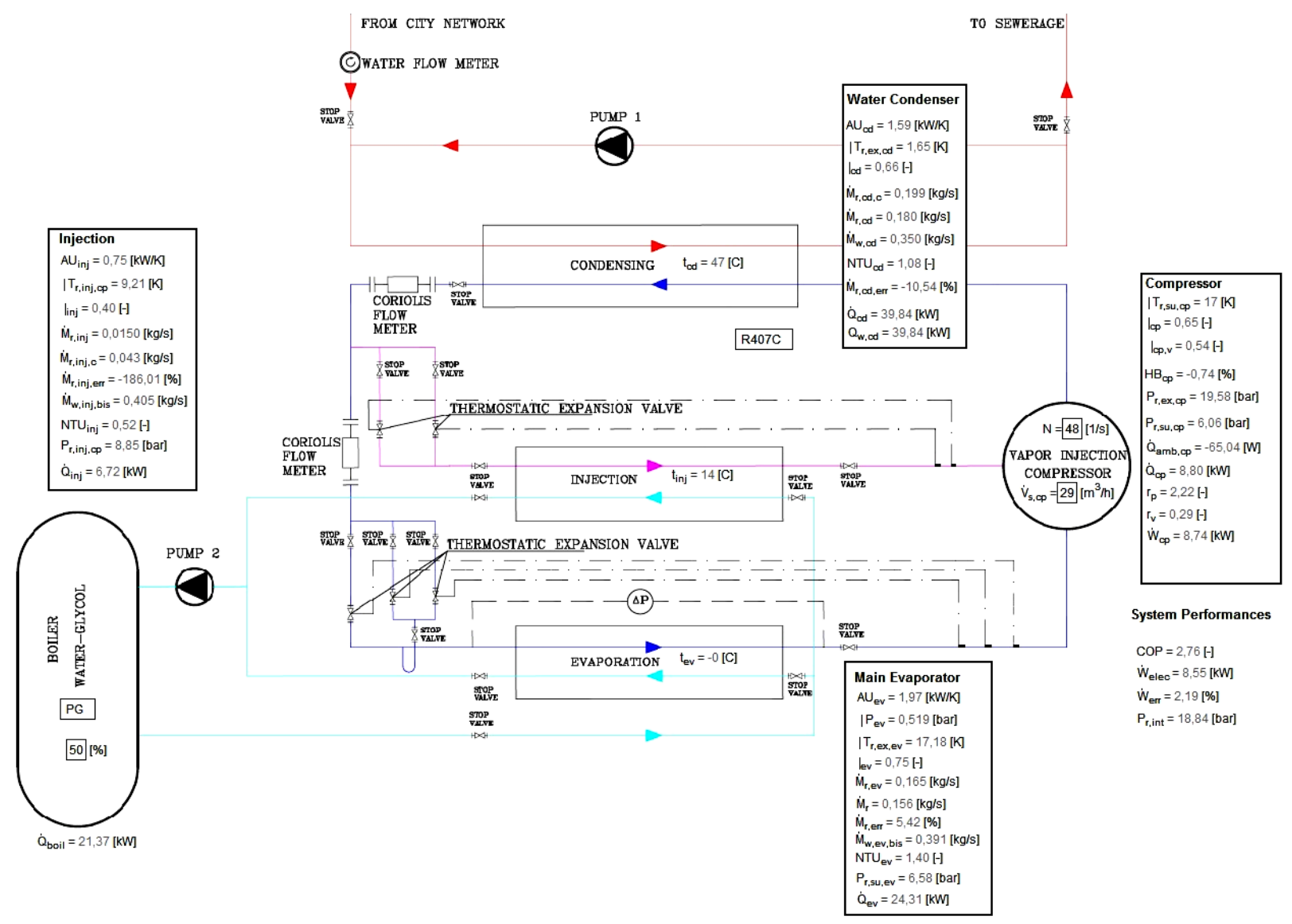

Fig. 1. Experimental bench diagram

Table 1. Parameters associated with the mathematical simulation model of the vapour-injected scroll compressor.

\begin{tabular}{|c|c|c|c|c|c|c|c|}
\hline $\begin{array}{c}\mathrm{V}_{\mathrm{s} ; \mathrm{cp}} \\
\mathrm{m}^{3} / \mathrm{h}\end{array}$ & $\begin{array}{c}\mathrm{k}_{\mathrm{amb} ; \mathrm{cp} ; \mathrm{n}} \\
\mathrm{W} \mathrm{K}^{-1}\end{array}$ & $\begin{array}{c}\dot{Q}_{r ; c p ; n} \\
\mathrm{~kg} \mathrm{~s}^{-1}\end{array}$ & $\begin{array}{c}\mathrm{r}_{\mathrm{v} ; \mathrm{in} ; \mathrm{cp}} \\
-\end{array}$ & $\begin{array}{c}\mathrm{W}_{\text {loss;cp }} \\
\mathrm{W}\end{array}$ & $\begin{array}{c}\alpha_{\mathrm{cp}} \\
-\end{array}$ & $\begin{array}{c}\mathrm{r}_{\mathrm{v} ; \text { in } 1 ; \mathrm{cp}} \\
-\end{array}$ & $\begin{array}{c}\mathrm{N} \\
\mathrm{min}\end{array}$ \\
\hline 29 & 80 & 0.091 & 4,21 & 8,596 & $10^{-3}$ & 0,92 & 2900 \\
\hline
\end{tabular}

\section{Mathematical simulation results}

The next figures present a comparison for the heat exchanger model between four refrigerants: R404A, R407C, R410A and R507A. [1]

The input values on the refrigerant side are: evaporation pressure from 3 bar to $7 \mathrm{bar}$, condensing pressure from 11 bar to 17 bar, primary fluid inlet temperature $6^{\circ} \mathrm{C}$ to $24^{\circ} \mathrm{C}$, superheating temperature from $18^{\circ} \mathrm{C}$ to $28^{\circ} \mathrm{C}$, sub-cooling temperature from $2^{\circ} \mathrm{C}$ to $4^{\circ} \mathrm{C}$.

The input values on the secondary fluid (water R718) side are: water inlet temperature from $12^{\circ} \mathrm{C}$ to $40^{\circ} \mathrm{C}$, water outlet temperature from $6^{\circ} \mathrm{C}$ to $31^{\circ} \mathrm{C}$, propylene-glycol concentrations at $50 \%$.

The results of the simulation of the evaporator associated with the injection are conveyed graphically and mathematically.

The mathematical polynomial for Fig. 2 is:

$\alpha_{e}=A+B \cdot N u_{a i}^{0,85}+C \cdot \ln \left(N u_{a i}\right)-D \cdot N u_{a i}^{0,32}$
The polynomial coefficients in equation (1) are given in Table 2 for each refrigerant in the graphic (Fig2).

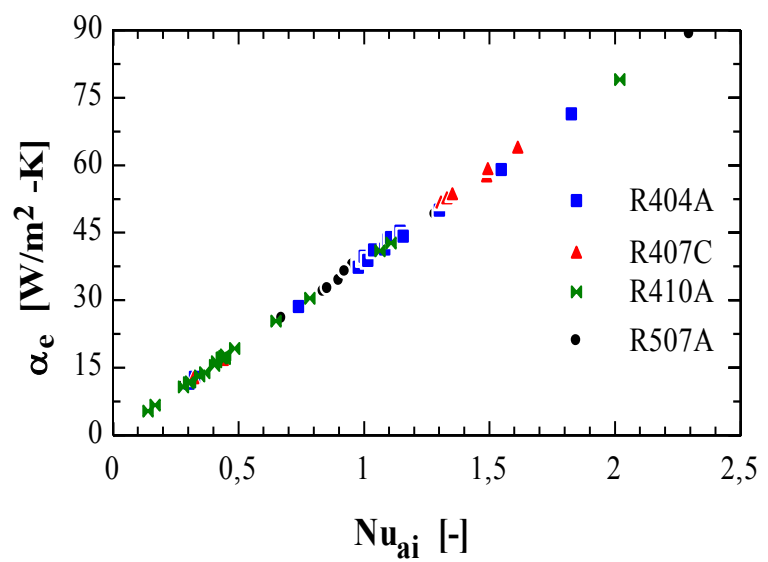

Fig. 2. Heat-transfer convective coefficient $\left(\alpha_{e}\right)$ on secondary refrigerant side according to the Nusselt number $\left(\mathrm{Nu}_{\mathrm{ai}}\right)$ 
Table 2. Polynomial coefficients from equation (1)

\begin{tabular}{|l|l|l|l|l|}
\hline Refrigerant & A & B & C & D \\
\hline R404A & 178,138 & 86,653 & 36,616 & 225,781 \\
\hline R407C & $-35,583$ & 50,420 & $-10,551$ & $-24,540$ \\
\hline R410A & 78,933 & 71,503 & 14,038 & 111,642 \\
\hline R507A & 46,476 & 64,189 & 7,549 & 71,687 \\
\hline
\end{tabular}

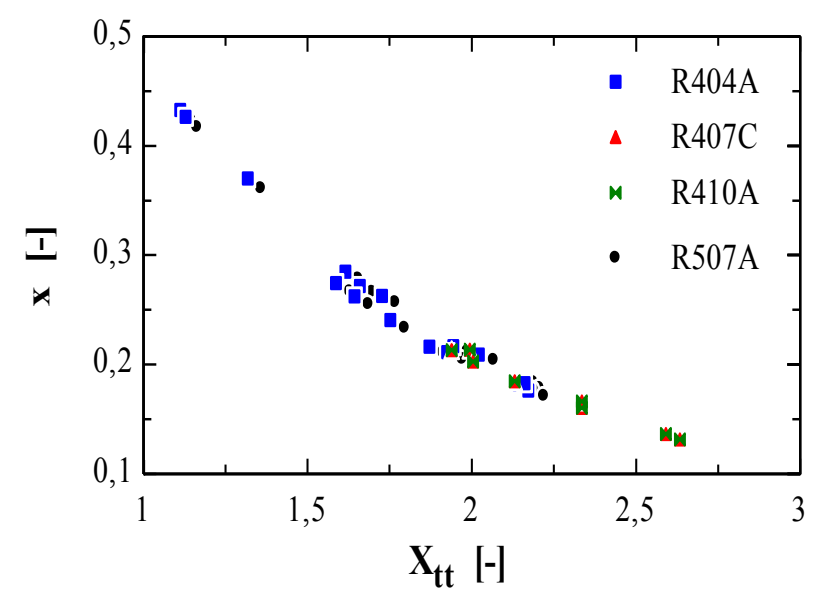

Fig. 3. Quality vapour title $(x)$ according to the Lockhart-Martinelli coefficient $\left(\mathrm{X}_{\mathrm{tt}}\right)$

The mathematical polynomial for Fig. 3 is: $x=-A+B \cdot X_{t t}-C \cdot X_{t t}{ }^{2}+D \cdot X_{t t}{ }^{3}-E \cdot X_{t t}{ }^{4}+F \cdot X_{t t}{ }^{5}-G \cdot X_{t t}{ }^{6}$

The polynomial coefficients in equation (2) are given in Table 3 for each refrigerant in the graphic (Fig.3).

Table 3. Polynomial coefficients from equation (2)

\begin{tabular}{|c|c|c|c|c|}
\hline Refrigerant & $A$ & $B$ & $C$ & $D$ \\
\hline $\mathrm{R} 404 \mathrm{~A}$ & 98 & 376 & 589 & 486 \\
\hline $\mathrm{R} 407 \mathrm{C}$ & 140170 & 375438 & 417835 & 247315 \\
\hline R410A & 140170 & 375438 & 417835 & 247315 \\
\hline R507A & 101 & 378 & 578 & 467 \\
\hline Refrigerant & $E$ & $F$ & $G$ & \\
\hline R404A & 224 & 54 & 5 & \\
\hline $\mathrm{R} 407 \mathrm{C}$ & 82109 & 14497 & 1063 & \\
\hline R410A & 82109 & 14497 & 1063 & \\
\hline R507A & 210 & 50 & 5 & \\
\hline
\end{tabular}

In the figure 4 are plots the polynomial equation (3) to the vapour-injected scroll compressor for refrigerant R407C.

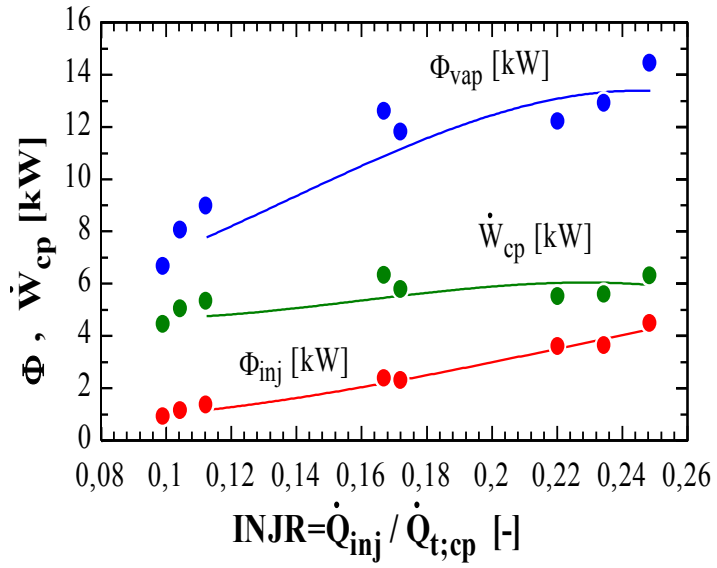

Fig. 4. The influence of the injection ratio upon the refrigerating capacity of the evaporator, of the injection valve and upon the mechanical work and the COP of the simulated system

$$
\begin{aligned}
& X=-\frac{A \cdot \dot{Q}_{t ; c p}}{\dot{\mathrm{Q}}_{i n j}}+B \cdot\left(\frac{\dot{\mathrm{Q}}_{i n j}}{\dot{Q}_{t ; c p}}\right)^{2}+C \cdot\left(\frac{\dot{\mathrm{Q}}_{i n j}}{\dot{Q}_{t ; c p}}\right)^{4}+ \\
& +D \cdot \ln \left(\frac{\dot{\mathrm{Q}}_{i n j}}{\dot{Q}_{t ; c p}}\right)+E \cdot \frac{\left(\frac{\dot{\mathrm{Q}}_{i n j}}{\dot{Q}_{t ; c p}}\right)^{6}}{\ln \left(\frac{\dot{\mathrm{Q}}_{i n j}}{\dot{Q}_{t ; c p}}\right)+F \cdot\left(\frac{\dot{\mathrm{Q}}_{i n j}}{\dot{Q}_{t ; c p}}\right)^{9}}
\end{aligned}
$$

Table 4. Polynomial coefficients from equation (3)

\begin{tabular}{|l|l|l|l|}
\hline $\boldsymbol{X}$ & $\boldsymbol{A}$ & $\boldsymbol{B}$ & $\boldsymbol{C}$ \\
\hline$\Phi_{\text {vap }}$ & 5,46241368 & $-2895,24228$ & 122688,743 \\
\hline$\Phi_{\text {inj }}$ & 4,0569973 & $-1614,45934$ & 56496,9998 \\
\hline $\mathrm{W}_{\text {cp }}$ & 1,89424882 & $-1128,94804$ & 48441,8571 \\
\hline $\boldsymbol{X}$ & $\boldsymbol{D}$ & $\boldsymbol{E}$ & $\boldsymbol{F}$ \\
\hline$\Phi_{\text {vap }}$ & $-34,7136341$ & 3360302,11 & 74003569 \\
\hline$\Phi_{\text {inj }}$ & $-22,8183137$ & 1326326,95 & 26985928,5 \\
\hline $\mathrm{W}_{\text {cp }}$ & $-13,3669318$ & 1336591,90 & 29487745,3 \\
\hline
\end{tabular}

\section{Conclusions}

The mathematical simulation model described in this paper can be used on any one stage compression refrigeration system if the parameters of the system have been determined (Table 1).

As a result of the simulations of the refrigeration systems performances, we found that several criteria for 
polynomials (the convective heat-transfer coefficient, mechanical work, refrigerating capacity) are essential in order to determine the refrigeration system performances [2].

For each type of analysed equipment, interpolating polynomials were set, which allow the calculation some parameters and coefficients related to the flow models in scroll evaporators and compressors. that:

According to the results of the analysis we found

- Injection ratio of both the injected and the theoretical refrigerant mass flow rates could increase along with the evaporating refrigerating capacities and with the mechanical power of the compressor;

- The mass flow rates related to the condensation, evaporation and injection processes increase along with the injection ratio. The interpolating polynomials for the convective coefficient of heat-transfer according to the Nusselt number associated with the secondary refrigerant, which were used for the simulation of the evaporator, are available for the analysed model, for the secondary refrigerant $\quad(50 \%$ propylene-glycol concentration) and for the refrigerants used in the survey.

The evaporator capacity (calculated according to the SR EN 305:2000 Standard) [3] increases along with the number of heat-transfer units. The resulted logarithmic equations were validated only for the analysed type of evaporator and for the four refrigerants. The analysed evaporator works at full capacity with the R407C refrigerant and at low capacity with the R410A refrigerant.

Quality vapour title swing in inverse ratio to Lockhart-Martinelli (Xtt) parameter.

This work leads the way to a new research direction in the domain of refrigeration system optimization associated with the vapour-injection process for scroll compressors, such as:

- Simplification of calculation procedures that should contain a smaller number of parameters and equations;

- Analyses of the operating performances of airconditioning systems, of the heat pumps and refrigeration systems with scroll compressors for different ecologic refrigerants (with zero ODP and reduced GWP).

\section{Acknowledge}

We wish to render thanks to the team of professors and researchers from the Department of Fluid Thermodynamics in charge of which is Engineer Vincent Lemort, PhD, to whom I would like to thank for both his physical and moral support and his extremely useful pieces of advice. I also give thanks to $\mathrm{PhD}$ Sylvain Quoilin, Assistant Professor, without whom the accomplishment of the experimental stand and the achievement of most of the scientific results would not have been possible.

As for the technical support I would like to thank to Eng. Eric Winandy, PhD, Director at Emerson Climate Technologies, and Head of the Applied Engineering Department at «Emerson Climate » on the time.

\section{References}

[1]. Engineering Equation Solver version 8.940

[2].I. Zabet, "Contributions to the study regarding the increase of eco-efficiency in refrigeration systems", $\mathrm{PhD}$ Thesis, Bucharest, (2012)

[3]. SR EN 305:2000 - Heat exchangers. Definitions of performance of heat exchangers and the general test procedure for establishing performance of all heat exchangers 